\title{
PEDOGEOQUÍMICA EM PERFIS DE ALTERAÇÃO NA REGIÃO DE LAVRAS (MG). I - ELEMENTOS MAIORES - ÓXIDOS CONSTITUINTES ${ }^{(\mathbf{1})}$
}

\author{
M. P. C. LACERDA(2), H. ANDRADE ${ }^{(3)}$ \& J . J . G. QUÉ MÉ NE UR ${ }^{(4)}$
}

\begin{abstract}
RESUMO
Na região de Lavras (MG), realizou-se a investigação do comportamento geoquímico ao longo dos processos de alteração e evolução pedológica em perfis de solos com horizonte B textural, discriminados pelo material de origem, individualizados em composição geoquímica ácida, intermediária e básica. Ao longo de cada perfil, realizaram-se análises geoquímicas de elementos maiores óxidos constituintes, avaliando perdas e ganhos mediante o cálculo do balanço químico de massa. As interpretações dos dados geoquímicos nos três perfis estudados revelaram perda moderada de $\mathrm{SiO}_{2}$, lixiviação de bases e enriquecimento relativo discreto do $\mathrm{Al}$, Fe e Ti, além de possibilitar o estabelecimento da ordem de perda desses constituintes.
\end{abstract}

Termos de indexação: solos com horizonte B textural, Argissolos, espectrometria de fluorescência de raios-X (FRX), espectroscopia de emissão atômica com plasma de acoplamento indutivo (ICP), balanço químico de massa, pedogênese.

\section{SUMMARY: PEDOGEOCHEMICAL IN ALTERATION PROFILES IN THE REGION OF LAVRAS, MINAS GERAIS. I - MAJ OR ELEMENTS - MAIN OXIDES}

The geochemical behavior in soil alteration profiles in Lavras (MG), Brazil, was evaluated during the process of soil formation leading to theformation of argillic horizons,

(1) Parte da Tese de Doutorado apresentada pela primeira autora ao Curso de Pós-Graduação em Solos e Nutrição de Plantas do Departamento de Ciência do Solo da Universidade Federal de Lavras - DCS-UFLA. Recebido para publicação em dezembro de 2000 e aprovado em agosto de 2001.

(2) Professora da Faculdade de Agronomia e Veterinária da Universidade de Brasília - FAV/UnB. Campus Darcy Ribeiro - ICC Sul. Caixa Postal 04508, CEP 70910-970 Brasília (DF). E-mail: marilusa@unb.br

(3) Professor do Departamento de Ciência do Solo da Universidade Federal de Lavras - UFLA. Caixa Postal 37, CEP 37200-000 Lavras (MG). E-mail: handrade@ufla.br

(4) Professor do Departamento de Geologia do I nstituto de Geociências da Universidade Federal de Minas Gerais - DG/IGC/UFMG. Av. Antônio Carlos 6.627, Caixa Postal 2608, CEP 31270-901 Belo Horizonte (MG). 
in parent material ranging from acid, intermediateto mafic geochemical composition. Al ong each profile, from the consolidated bedrock to the solum, geochemical analyses of major elements-main oxides were performed, calculating the gains and losses through a mass chemical balance. Theresults showed a moderateloss of $\mathrm{SiO}_{2}$, bases leaching, and a slight relativeenrichment of $\mathrm{Al}, \mathrm{Fe}$ and $\mathrm{Ti}$. Thel eaching order of thesee ements from thealterites was al so established.

Index terms: argillic horizon, ultisols, X-ray fluorescence spectrometry (XRF), Atomic emission spectroscopy with inductive coupled plasm (ICP), Chemical balance, pedogenesis.

\section{INTRODUÇÃO}

A geoquímica de superfície e sua ramificação, denominada Pedogeoquímica, revestem-se de grande importância no estudo da pedogênese, permitindo o entendimento dos processos de alteração que ocorrem ao longo da evolução pedológica, pois avaliam o comportamento dos el ementos químicos, a partir da distribuição e migração destes el ementos, eas reações quími cas envol vidas ao longo do processo evolutivo, desde a rocha fresca até o sólum.

No ambiente natural de superfície crustal, as condi ções físi co-químicas rei nantes permitem a ação do intemperismo e, na maioria das vezes, o desenvol vimento de atividades de organismos vivos. Neste ambiente, as rochas primárias, formadas a temperaturas e pressões bem superiores, vão estar em permanente desequilíbrio, quese acentua quando entram em contato com as águas meteóricas, dando início ao processo de meteorização ou intemperismo, que vai permitir a pedogênese.

A meteorização de minerais primários libera cátions constituintes da estrutura dos minerais; entretanto, nem todos os cátions são solubilizados com a mesma intensidade. Alguns tendem a ser prontamente lixiviados pelas águas de percolação, enquanto outros são resistentes e tornam-se progressivamente concentrados no resíduo (Loughnan, 1969).

Várias tentativas têm si do feitas para determinar empiricamente a ordem de perda de constituintes ao longo do processo de alteração de rochas e da pedogênese. O trabalho pioneiro de Polynov (1937) comparou a composição média de matéria mineral dissol vi da em rios e concentrados em bacias em áreas de rochas maciças, com a composi ção média de rochas ígneas, e obteve a seguinte ordem de perda de constituintes: $\mathrm{Ca}^{2+}>\mathrm{Na}^{+}>\mathrm{Mg}^{2+}>\mathrm{K}^{+}>\mathrm{SiO}_{2}>\mathrm{Fe}_{2} \mathrm{O}_{3}$ $>\mathrm{Al}_{2} \mathrm{O}_{3}$.

Esta seqüência está de acor do com as seqüências clássicas de ordem de intemperização de minerais primários, obtidas por Goldich (1938), a partir de estudos da alteração de granito-gnaisse em Minnesota, e por Tyler (1958), citado por Loughnan (1969), a partir de alteração de material basáltico do Sul da Austrália.
Considerando os diversos fatores químicos envolvidos na meteorização de minerais primários, a extensão da alteração química e a natureza do produto residual formado irão depender do grau de lixiviação sofrido pela rocha. É notória a mobilidade dos elementos durante os processos intempéricos, especialmente no intemperismo químico. Para determinar a distribuição e migração desses elementos ao longo da meteorização química, podese recorrer ao balanço químico de massa, que é definido pela relação ou diferença entre o ganho e perda de el ementos durante a al teração do material original até o material residual de intemperismo, resultante da mobilidade dos el ementos quando submetidos ao intemperismo químico. Os fatores que influem na mobilidade dos el ementos são agrupados em quatro categorias: (a) ordem atômicaiônica, tais como: raio iônico, grau de oxidação e potencial iônico; (b) ordem cristalográfica, inerente ao grau de cristalinidade do mineral; (c) ordem litológica, referente à granulometria, porosidade, permeabilidade e composição química global da rocha, e (d) ordem ambiental, relativa à temperatura, índice de pluviosidade, atividadeorgânica, fisiografia local e características físico-químicas (pH, Eh) das sol uções meteóri cas de percol ação (Carval ho, 1995).

Objetivando entender a natureza da geoquímica da al teração de rochas ea sua relação com a gênese de sol os da região de Lavras (MG), uma vez que não existem trabal hos que contemplem tal tema nesta região, realizaram-se estudos pedogeoquímicos em perfis dealteração em sol os com horizonte $B$ textural de ocorrência regional, desenvolvidos a partir de materiais de origem litoquimicamente distintos: rochas ígneas de composição ácida, intermediária e básica. Nesta região, esses sol os desenvol vem-sesob relevo ondulado a forteondulado, originando distintas dasses de solos com horizonte $B$ textural em função do substrato, discriminado petrológica e geoquimicamente.

Realizou-se a caracterização geoquímica detodos os horizontes que compõem os perfis de alteração, desde a rocha fresca atéo sólum, eaval iou-se a variação de sua composição química ao longo da seqüência de alteração. Analisaram-se, também, o comportamento da mobilidade, a distribuição dos el ementos químicos e a quantificação de suas perdas e ganhos. 


\section{MATERIAL E MÉTODOS}

Os perfis selecionados para o estudo do comportamento geoquímico ao longo da alteração pedogenética foram aqueles correspondentes às classes desolo com horizonteB textural deocorrência na região estudada, ou seja: Perfil 1 - Argissolo Vermelho-Amarelo distrófico (PVAd), formado a partir de rochas granitóides de composição granítica (rocha ígnea de composi ção ácida, teor de $\mathrm{SiO}_{2}>66 \%$ ) do Domínio geológico intitulado Granito de l tutinga (Queméneur, 1995; Lacerda, 1999); Perfil 2 Argissolo Vermel ho eutrófico (PVe), desenvolvido sobre di orito milonitizado (rocha ígnea de composição intermediária, com 55 a $66 \%$ de $\mathrm{SiO}_{2}$ ) do Domínio geológico Diorito do Rosário (Queméneur, 1995; Lacerda, 1999), e Perfil 3 - Chernossolo Argilúvico férrico (MTf), evoluído sobre piroxenito granulitizado (rocha ígnea básica, com teor de $\mathrm{SiO}_{2}$ entre 55 a 45\%) do Domínio geológico denominado Greenstonebelt de L avras (Queméneur, 1995; L acerda, 1999).

O material utilizado constituiu-se da amostragem feita ao longo dos perfis de al teração, desde as rochas frescas do substrato e seus diferentes estádios de alteração e os solos sobre elas desenvolvidos, individualizados em seus horizontes. Os perfis de alteração foram criteriosamente sel ecionados, partindo da discriminação geoquímica e petrológica dos domínios geológi cos de origem.

As coordenadas geográficas dos perfis são: Perfil 1 - Argissolo Vermel ho-Amarelo distrófico: 4435'28" W e 21017'50"S; Perfil 2 - ArgissoloVermel ho eutrófico: 44053'00" W e 21016'38" S, e Perfil 3 - Chernossolo Argilúvico férrico: 4502'56"W e 21011'00" S.

Foram realizadas excursões de campo para selecionar os perfis de alteração, observando-se os diferentes substratos geológicos e as respectivas classes de solo formadas, bem como os padrões de relevo associados ao desenvolvimento de sol os com horizonte B textural na região, ou seja, relevo ondulado a forte ondulado (Andrade et al., 1998).

A amostragem para as análises geoquímicas foi feita ao longo dos horizontes de cada perfil, col etando-se amostras representativas desde a rocha fresca até o sólum, baseando-se em observações dos estádios de alteração, tais como: características texturais preservadas das rochas originais, composição mineralógica original, col oração, friabilidade e características morfol ógicas do sólum.

Foram coletadas amostras indeformadas em todos os horizontes que compõem os perfis de alteração, além de amostras de rochas alteradas e rochas frescas ou inalteradas, para a avaliação de suas densidades gl obais.

\section{Análises geoquímicas}

As amostras de sol o para as anál ises geoquímicas foram secas ao ar e, posteriormente, pulverizadas manualmente em graal de ágata até atingir granulometria menor que 0,105 mm, com controle granulométrico por tamisagem a seco (tamis de 150 \#), sendo, então, individualizadas alíquotas de cerca de $30 \mathrm{~g}$. As amostras de rocha fresca e rocha alterada foram britadas e pulverizadas em moinho de W no Centro de Pesquisas Manoel Teixeira da Costa/I nstituto de Geociências/U niversidadeFederal de Minas Gerais - CPMTC/IGC/UFMG, sendo, também, individualizadas alíquotas de cerca de $30 \mathrm{~g}$.

As análises geoquímicas foram efetuadas no CPMTC/I GC/UFMG, utilizando métodos combi nados de Espectrometria de Fluorescência de Raios-X (FRX) e Espectroscopia de Emissão Atômica com Plasma de Acoplamento I ndutivo (ICP). Os elementos maiores analisados, expressos em óxidos constituintes, foram: $\mathrm{SiO}_{2}, \mathrm{Al}_{2} \mathrm{O}_{3}, \mathrm{Fe}_{2} \mathrm{O}_{3}, \mathrm{CaO}, \mathrm{MgO}$, $\mathrm{Na}_{2} \mathrm{O}, \mathrm{K}_{2} \mathrm{O}, \mathrm{TiO}_{2}, \mathrm{MnO}_{2} \mathrm{P}_{2} \mathrm{O}_{5}$, além da perda ao fogo.

\section{Teores absolutos - Balanço químico de massa}

Nas análises químicas convencionais, no caso dos elementos maiores-óxidos constituintes, a comparação dos resultados analíticos de duas amostras pode levar a estimativas ambíguas, pois tais resultados não são padronizados para unidades de massa equivalente, isto é, as diferenças de distribuição composicional dos componentes químicos impostos pela alteração intempérica não são levadas em consideração. É pouco provável que a alteração intempérica de 100 g de uma rocha irá produzir $100 \mathrm{~g}$ de produto alterado, pois os componentes de diferentes pesos moleculares podem ser trocados da rocha fonte para o produto. Variações na densidade e sua relação com as mudanças de volume irão, deste modo, constituir parâmetros fundamentais na obtenção da padronização da rocha fonte e seus produtos, em uma unidade de massa equivalente.

Foram, então, calculadas as quantidades absolutas de cada componente químico de toda a seqüência de alteração nos perfis 1, 2 e 3, pela multiplicação dos teores dos elementos obtidos na análise química com os valores de densidade das respectivas amostras.

Desta forma, os valores da densi dade da amostra foram incorporados ao cálculo de perdas e ganhos dos elementos da rocha original para os produtos alterados, com vistas em fixar a variação de volume.

Para a avaliação quantitativa da mobilidade dos elementos químicos durante a evolução do processo pedogenético ao longo dos perfis de alteração estudados, partindo da rocha fresca de origem, foram efetuados cálculos de balanço químico de massa. Utilizou-se o cálculo isovolumétrico proposto por Millot \& Bonifas (1955) e Bonifas (1959), mediante a expressão: $t \%=100\left[\left(d_{a} \cdot x_{a} / d_{0} \cdot x_{0}\right)-1\right]$; em que t\% = taxa de mobilidade; $d_{a}=$ densidade para o produto dealteração; $d_{0}=$ densidade para o material original; $\mathrm{x}_{\mathrm{a}}=$ teor do el emento no produto de al teração; e $\mathrm{x}_{\mathrm{o}}=$ 
teor de elemento no material original. Este cálculo de balanço químico de massa permite determinar perdas e ganhos em termos absolutos dos el ementos constituintes do material, em que t\% define a percentagem de perda, quando negativo, e ganho, quando positivo, dos componentes químicos nos vários estádios de alteração em relação ao seu material original.

O cálculo isovolumétrico proposto por Millot \& Bonifas (1955) e Bonifas (1959) é utilizado quando se têm evidências de que a variação de volume é desprezível, tal como a conservação da estrutura do material durantea alteração, sendo possível cal cular a quantidade, em peso, de cada elemento por unidade de vol ume, e compará-la com a quantidadeno mesmo volume de rocha fresca.

O método foi utilizado com base nos estudos micropedológicos e mineralógicos realizados na mesma seqüência de amostras destes perfis de alteração, cujos método e resultados encontram-se detal hados em Lacerda (1999) e Lacerda et al. (2000), que permitiram aos autores observar razoável conservação de estrutura litológica nos estádios iniciais de alteração, ou seja, no al terito (horizontes pedológi $\cos \mathrm{C}$ ). Na evol ução da alteração, representada pelos horizontes de transição (horizonte BC) e sól um (horizonte $B_{t}$ eA), foi possível observar feições indicativas de preservação de volume, tais como: box works e aumento gradativo na proporção de vazios em relação ao plasma +esquel eto no fundo matricial.

\section{Análises físicas}

A determinação da densidade global das amostras foi efetuada pelo método do torrão parafinado (EM BRAPA, 1979a), com três repetições por amostra.

\section{Características físicas e mineralógicas dos perfis de alteração}

As características físicas, assim comoa mineralogia da seqüência de alteração destes perfis, foram avaliadas por Lacerda (1999) e Lacerda et al. (2000). O quadro 1 sumaria as principais características físicas destes perfis.

A mineralogia dos fácies rocha-fresca dos perfis estudados apresenta a seguinte composição:

- Perfil 1 (PVAd) - granitóide- mineral ogia essencial: feldspato potássico (30\%), plagioclásio (35\%), quartzo (25\%), biotita e anfibólio relictual da série hornblenda-edenita (5\%); mineral ogia secundária (5\%): biotita, epidoto da série zoisita-pistacita e zoisita-clinozoisita, moscovita, sericita, carbonato, titanita, clorita e óxidos de ferro, e mineralogia acessória: zircão e allanita.

- Perfil 2 (PVe) - diorito milonitizado - mineralogia essencial: plagioclásio (40\%), anfibólio da série

Quadro 1. Características físicas dos perfis 1, 2 e 3

\begin{tabular}{|c|c|c|c|c|c|c|c|c|c|}
\hline \multirow{2}{*}{ Amostra } & \multirow{2}{*}{ Horizonte } & \multirow{2}{*}{ Profundidade } & \multirow{2}{*}{ Areia } & \multirow{2}{*}{ Silte } & \multirow{2}{*}{ Argila } & \multirow{2}{*}{ Silte/argila } & \multicolumn{2}{|c|}{ Classificação textural } & \multirow{2}{*}{ D } \\
\hline & & & & & & & $\operatorname{SBCS}^{(1)}$ & EMBRAPA $^{(2)}$ & \\
\hline & & $\mathrm{cm}$ & $\longrightarrow$ & $\mathrm{g} \mathrm{kg}^{-1}$ & - & & & & $\mathrm{kg} \mathrm{dm}^{-3}$ \\
\hline \multicolumn{10}{|c|}{ Perfil 1 - Argissolo Vermelho-Amarelo distrófico(PVAd) } \\
\hline $\begin{array}{l}\mathrm{A} \\
\mathrm{B} \\
\mathrm{BC} \\
\mathrm{C}_{1} \\
\mathrm{C}_{2}\end{array}$ & $\begin{array}{l}A \\
B_{t} \\
B C \\
C_{1} \\
C_{2}\end{array}$ & $\begin{array}{c}0-55 \\
55-95 \\
95-130 \\
130-210 \\
210-310\end{array}$ & $\begin{array}{l}500 \\
560 \\
520 \\
660 \\
620\end{array}$ & $\begin{array}{l}320 \\
230 \\
360 \\
280 \\
330\end{array}$ & $\begin{array}{r}180 \\
210 \\
120 \\
60 \\
50\end{array}$ & $\begin{array}{l}1,78 \\
1,09 \\
3,00 \\
4,67 \\
6,60\end{array}$ & $\begin{array}{l}\mathrm{fr} \\
\mathrm{fr} \text {-arg-aren } \\
\text { fr-aren } \\
\text { fr-aren } \\
\text { fr-aren }\end{array}$ & $\begin{array}{l}\text { médio } \\
\text { médio } \\
\text { médio } \\
\text { médio } \\
\text { médio }\end{array}$ & $\begin{array}{l}1,38 \\
1,35 \\
1,27 \\
1,31 \\
1,25\end{array}$ \\
\hline \multicolumn{10}{|c|}{ Perfil 2 - Argissolo Vermel ho eutrófico (PVe) } \\
\hline $\begin{array}{l}A \\
B \\
B C \\
C_{1} \\
C_{2} \\
C_{3}\end{array}$ & $\begin{array}{l}\mathrm{A} \\
\mathrm{B}_{1} \\
\mathrm{BC} \\
\mathrm{C}_{1} \\
\mathrm{C}_{2} \\
\mathrm{C}_{3}\end{array}$ & $\begin{array}{c}0-20 \\
20-80 \\
80-130 \\
130-260 \\
260-430 \\
430-450\end{array}$ & $\begin{array}{l}300 \\
200 \\
240 \\
260 \\
260 \\
320\end{array}$ & $\begin{array}{l}400 \\
440 \\
590 \\
650 \\
670 \\
600\end{array}$ & $\begin{array}{r}300 \\
360 \\
170 \\
90 \\
70 \\
80\end{array}$ & $\begin{array}{l}1,34 \\
1,22 \\
3,47 \\
7,22 \\
9,57 \\
7,50\end{array}$ & $\begin{array}{l}\text { fr-arg } \\
\text { fr-arg a fr-arg-silt } \\
\text { fr-silt } \\
\text { fr-silt } \\
\text { fr-silt } \\
\text { fr-silt }\end{array}$ & $\begin{array}{l}\text { médio } \\
\text { médio a argiloso } \\
\text { médio } \\
\text { médio } \\
\text { médio } \\
\text { médio }\end{array}$ & $\begin{array}{l}1,28 \\
1,47 \\
0,97 \\
1,07 \\
1,06 \\
1,18\end{array}$ \\
\hline \multicolumn{10}{|c|}{ Perfil 3 - Chernossolo Argilúvico férrico (MTf) } \\
\hline$A$ & $A$ & $0-18$ & 480 & 360 & 160 & 2,25 & $\mathrm{fr}$ & médio & 1,25 \\
\hline B & $\mathrm{B}_{\mathrm{t}}$ & $18-55$ & 140 & 340 & 520 & 0,65 & $\arg$ & argiloso & 1,45 \\
\hline $\mathrm{BC}$ & BC & $55-85$ & 200 & 390 & 410 & 0,95 & arg & argiloso & 1,09 \\
\hline $\mathrm{C}_{1}$ & $\mathrm{C}_{1}$ & $85-120$ & 560 & 320 & 120 & 2,67 & fr-aren & médio & 1,09 \\
\hline $\mathrm{C}_{2}$ & $\mathrm{C}_{2}$ & $120-230$ & 700 & 260 & 40 & 6,50 & fr-aren & médio & 1,51 \\
\hline $\mathrm{C}_{3}$ & $\mathrm{C}_{3}$ & $230+$ & 740 & 220 & 40 & 5,50 & areia-fr & arenoso & 2,16 \\
\hline
\end{tabular}

$\mathrm{D}=$ densidade global do solo, arg = argiloso, $\mathrm{fr}=$ franco, silt =siltoso, aren =arenoso. ${ }^{(1)}$ Classes texturais do material constitutivo de horizontes e perfis de solos, segundo Lemos \& Santos (1984), adotadas pela Sociedade Brasileira de Ciência do Solo - SBCS. (2) Classificação textural simplificada, segundo EMBRAPA (1979b). 
hornblenda-edenita (20\%), quartzo (9\%) efeldspato potássico (traços); mineralogia secundária: epi doto da série zoisita-pistacita (15\%), biotita (5\%), titanita $(5 \%)$, sericita $(5 \%)$ e clorita $(1 \%)$, e mineralogia acessória: zircão, apatita e óxidos de ferro e titânio.

- Perfil 3 (MTf) - piroxenito granulitizado mineralogia essencial: clinopiroxênio da série diopsídio-augita (30\%), anfibólio da série hornblenda-edenita (30\%), plagioclásio (35\%) e quartzo (traços); mineralogia secundária (5\%): anfibólio da série tremolita-actinolita/uralita, sericita, óxidos de ferro e de titânio, e mineralogia acessória: apatita.

A associação de argilominerais silicatados mostra a seguinte constituição:

- Perfil 1 (PVAd): illita (nos horizontes C, BC e $B_{t}$ ) e caulinita + gibbsita (ambos nos horizontes C, BC, $B_{t}$ eA).

- Perfil 2 (PVe): illita (nos horizontes C e BC), vermiculita com hidróxi nas entrecamadas + caulinita (ambos nos horizontes C, BC, $B_{t}$ e A) e gibbsita (desenvolvida a partir do horizonte BC).

- Perfil 3 (MTf): caulinita + talco + esmectita (horizontes $\mathrm{C}_{3}, \mathrm{C}_{2}, \mathrm{C}_{1}, \mathrm{BC}, \mathrm{B}_{\mathrm{t}} \mathrm{eA}$ ).

\section{RESULTADOS E DISCUSSÃO}

Os resultados da análise química para os elementos maiores-óxidos constituintes (resultados normal izados para $100 \mathrm{dag} \mathrm{kg}^{-1}$ ) por meio de FRX e ICP para os perfis 1, 2 e 3 encontram-se listados no quadro 2. As amostras referem-se aos horizontes pedogenéticos $A, B$ (considerados como fácies sólum), BC (considerado como fácies de transição) e C (considerado como fácies alterito). $\mathrm{R}_{1}$ corresponde ao fácies rocha alterada e $R$ ao fácies rocha fresca de origem.

As quantidades absolutas de cada componente quími co detoda a seqüência deal teração nos perfis 1 , 2 e 3 encontram-se no quadro 3. Foram el aborados diagramas de teor absol uto dos el ementos maioresóxidos constituintes versus densidade global para os perfis 1, 2 e 3 (Figuras 1, 2 e 3), visto que a densidade da amostra é um parâmetro que reflete o grau de alteração de maneira sensível. Nestes diagramas, a densidadegl obal representa os diversos fácies de alteração avaliados ao longo dos perfis estudados, de acordo com a correspondência entre as densidades globais e suas respectivas amostras apresentadas no quadro 3.

Quadro 2. Dados analíticos (FRX e ICP) dos elementos maiores-óxidos constituintes - Perfis 1, 2 e 3

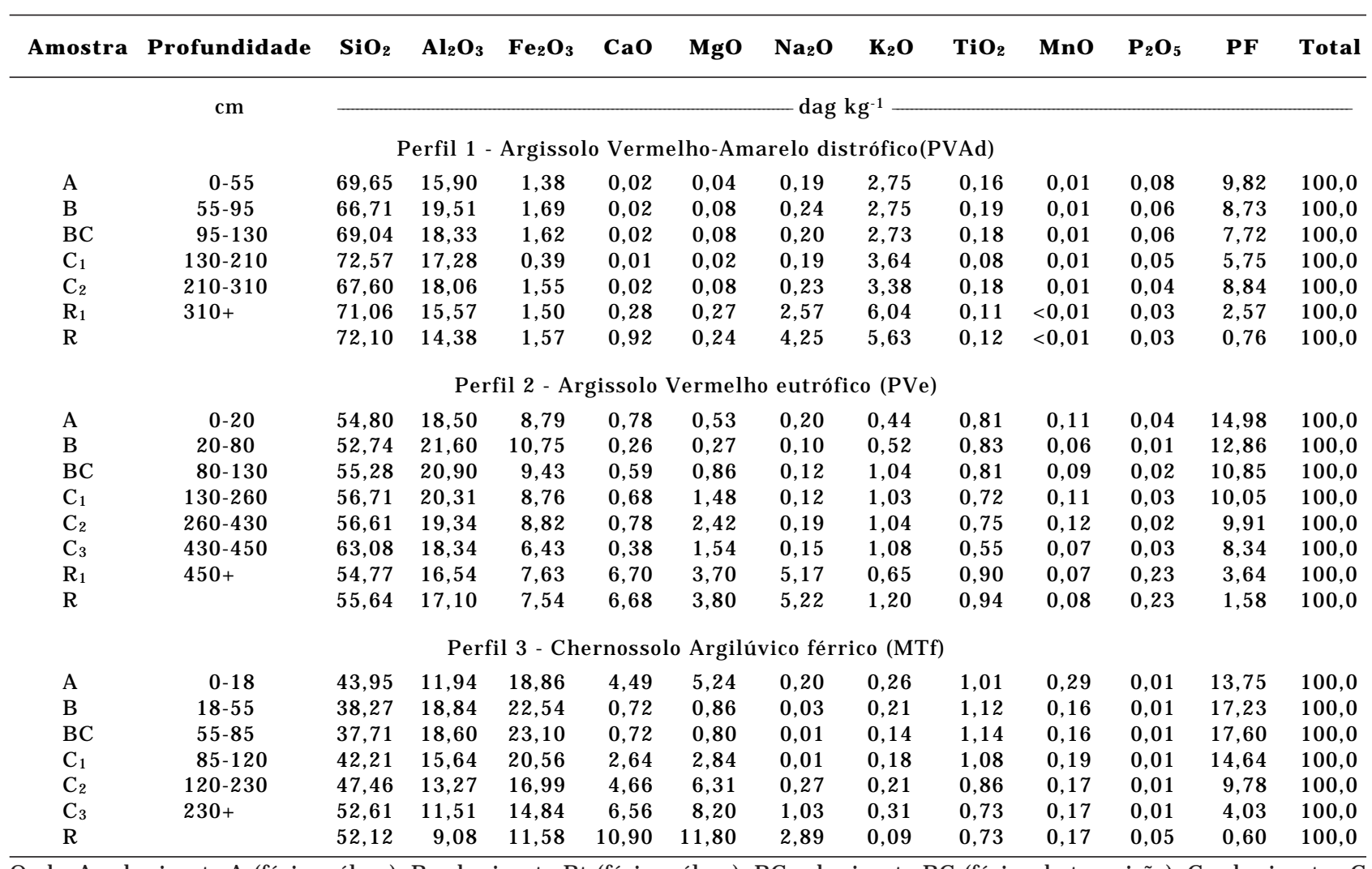

Onde: $\mathrm{A}=$ horizonte $\mathrm{A}$ (fácies sólum), $\mathrm{B}=$ horizonte $\mathrm{Bt}$ (fácies sólum), $\mathrm{BC}=$ horizonte $\mathrm{BC}$ (fácies de transição), $\mathrm{C}=$ horizontes $\mathrm{C}$ (fácies alterito), $R_{1}=$ fácies rocha alterada, $R=$ fácies rocha fresca de origem, $P F=$ perda ao fogo. 
Quadro 3. Teores absolutos dos elementos maiores-óxidos constituintes - Perfis 1, 2 e 3

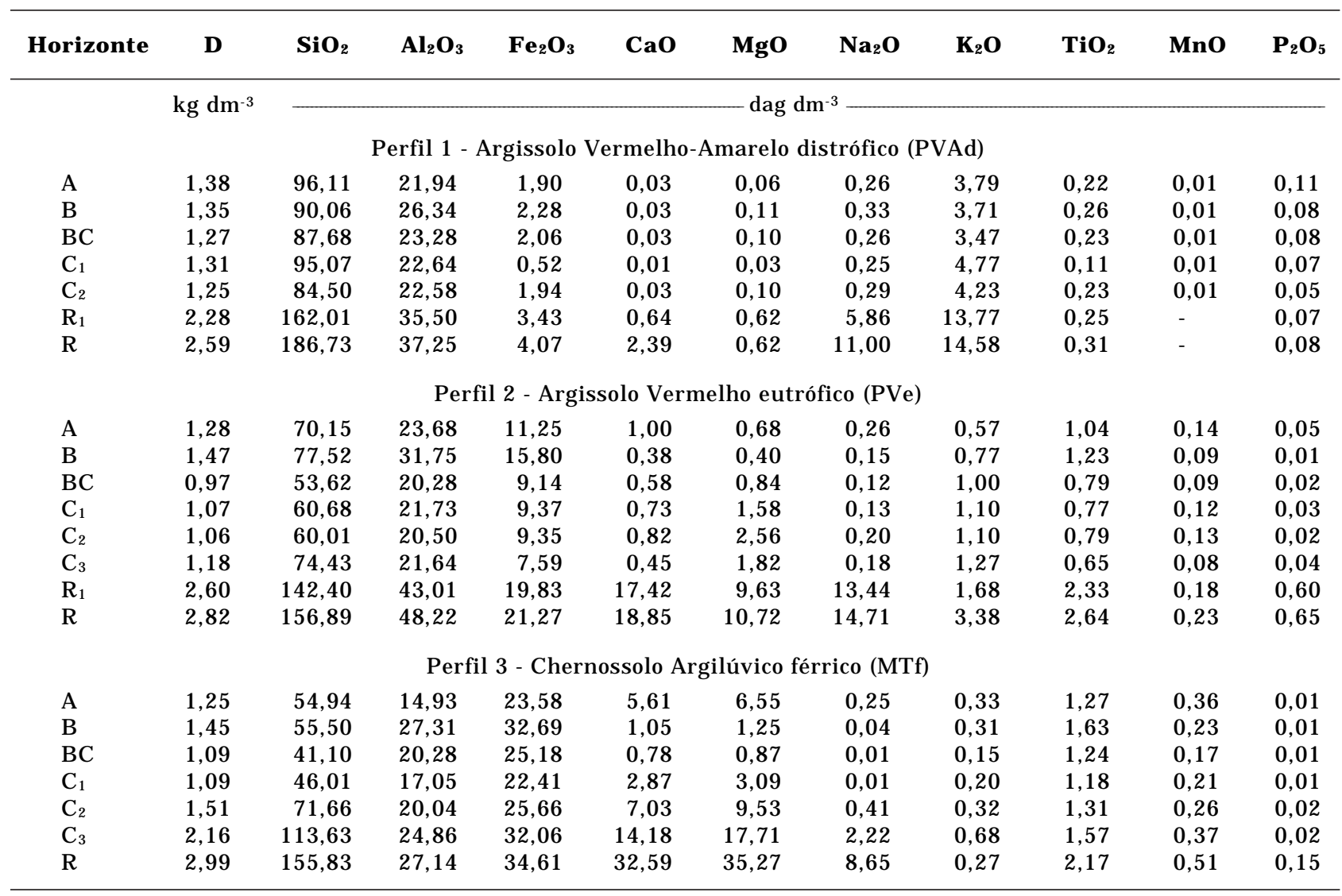

Onde: $\mathrm{A}=$ horizonte $\mathrm{A}$ (fácies sólum), $\mathrm{B}=$ horizonte Bt (fácies sólum), BC = horizonte BC (fácies de transição), $\mathrm{C}=$ horizontes $\mathrm{C}$ (fácies alterito), $R_{1}=$ fácies rocha alterada, $R=$ fácies rocha fresca de origem. $D=$ densidade global.

Os cálculos isovolumétricos de balanço químico de massa (Millot \& Bonifas, 1955; Bonifas, 1959), apresentados no quadro 4, permitiram determinar as perdas e ganhos em termos absolutos dos elementos maiores-óxidos constituintes ao longo dos perfis 1 , 2 e 3 .

Os teores absolutos dos el ementos maiores-óxidos constituintes (Quadro 3), dos diagramas de distribuição de acordo com a densidade, correspondentes à seqüência da evolução da alteração ao longo dos perfis 1, 2 e 3 (Figuras 1, 2 e 3) e do balanço químico de massa (Quadro 4), levam aos seguintes comentários:

$\mathrm{SiO}_{2}$ - A perda nos teores absolutos de $\mathrm{SiO}_{2}$ ocorreu nos perfis 1, 2 e 3 , cujos val ores ao longo da seqüência de alteração encontram-se no quadro 3 , sendo mais acentuada nos estádios iniciais da alteração, nos fácies de alteração rocha fresca ao

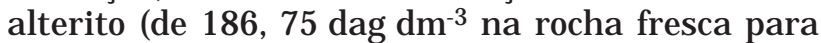
84,50 dag dm$^{-3}$ no horizonte $C_{2}$ do perfil 1 (PVAd); de $156,89 \mathrm{dag} \mathrm{dm}^{-3}$ na rocha fresca para $74,43 \mathrm{dag} \mathrm{dm}^{-3}$ no horizonte $C_{3}$ do perfil 2 (PVe), e de 155,88 dag dm ${ }^{-3}$

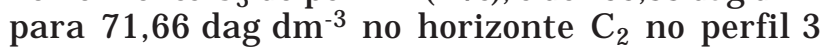

(MTf), permanecendo com decréscimo discreto atéo horizonte de transição BC, seguido de discretíssimo acréscimo em direção ao sólum (Figuras 1, 2 e 3).

O balanço químico (Quadro 4) mostrou ser essa perda moderada a partir do alterito. Entre os fácies de alteração rocha fresca e rocha alterada, a perda foi pequena, ea partir desta foi muito discretamente progressiva do alterito ao sólum, mostrando val ores ligeiramente mais baixos no horizonte $B_{t}$. As perdas médias verificadas foram de cerca de $50-60 \%$, atingindo $73 \%$ no horizonte BC do perfil 3 (MTf).

$\mathbf{A l}_{2} \mathbf{O}_{3}, \mathbf{F e}_{2} \mathbf{O}_{3} \mathbf{e} \mathbf{T i O}_{2}$ - Nos três perfis estudados, observou-se acrésci mo discreto nos teores absol utos desses elementos nos horizontes $B_{t}$, seguido de subseqüente decréscimo no horizonte $A$, após uma perda inicial, pouco significativa, da rocha fresca ao alterito, permanecendo, a partir do último, valores absolutos pouco variáveis até o horizonte BC; podendo-se constatar este comportamento no quadro 3 e nas figuras 1,2 e 3 .

A partir do balanço químico (Quadro 4), pôde-se quantificar tal comportamento. $\mathrm{OAI}_{2} \mathrm{O}_{3}$ experimentou perda moderada ao longo da seqüência de al teração 

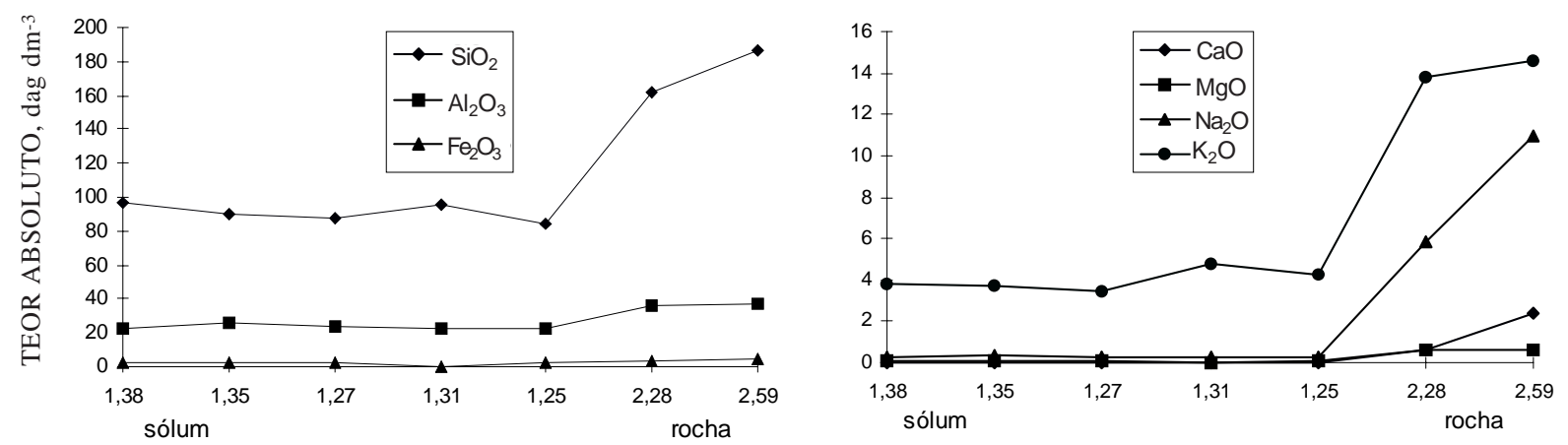

DENSIDADE, $\mathrm{kg} \mathrm{dm}^{-3}$

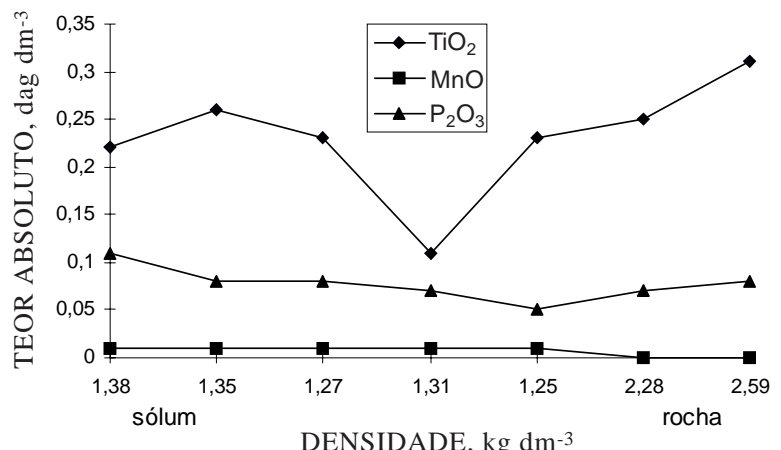

Figura 1. Diagramas de distribuição dos elementos maiores em teores absolutos versus densidade para o perfil 1 - PVAd.

Quadro 4. Balanço químico (isovolumétrico) dos elementos maiores-óxidos constituintes - Perfis 1, 2 e 3

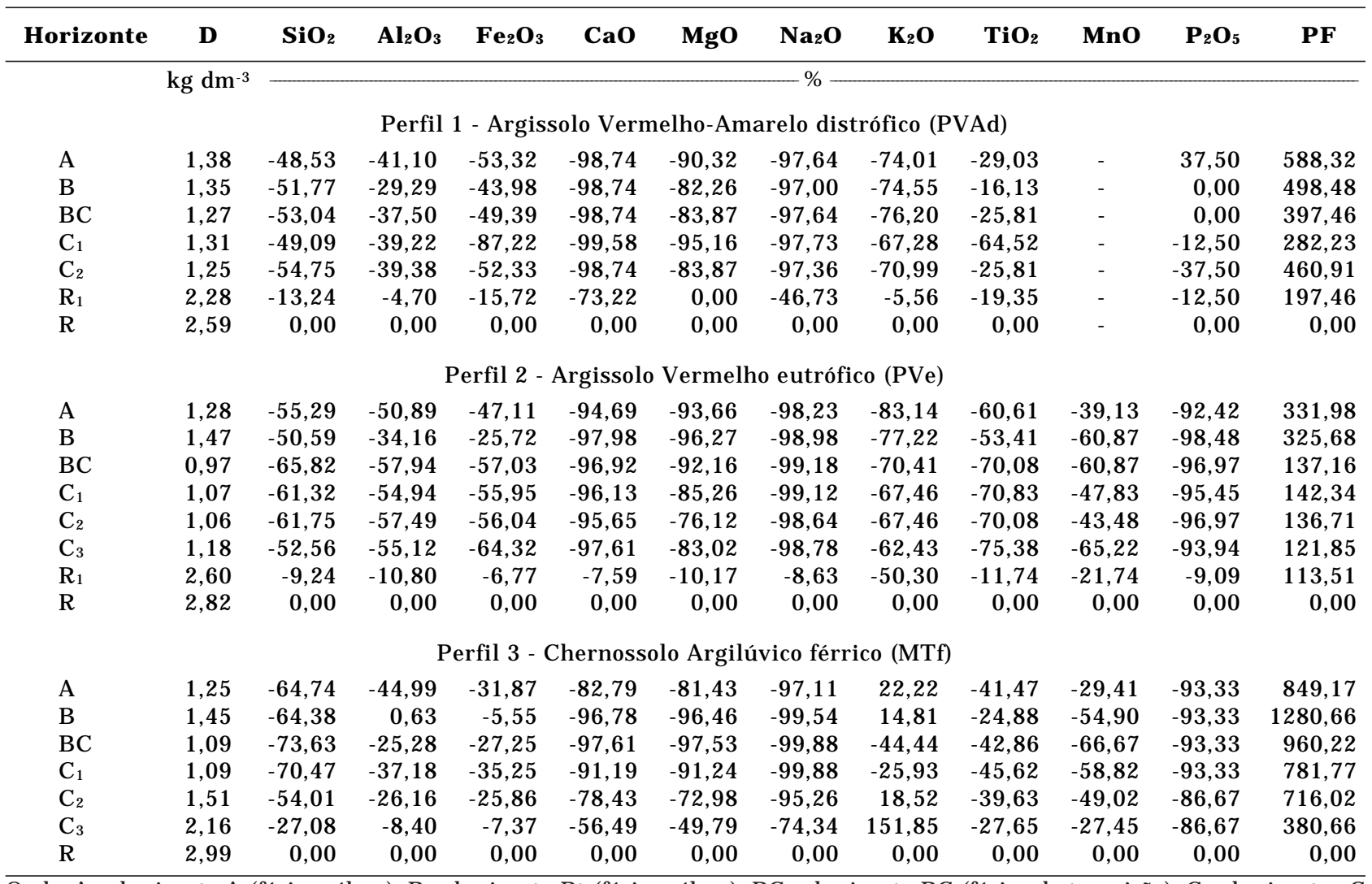

Onde: $\mathrm{A}=$ horizonte $\mathrm{A}$ (fácies sólum), $\mathrm{B}=$ horizonte Bt (fácies sólum), $\mathrm{BC}=$ horizonte $\mathrm{BC}$ (fácies de transição), $\mathrm{C}=$ horizontes $\mathrm{C}$ (fácies alterito), $R_{1}=$ fácies rocha alterada, $R=$ fácies rocha fresca de origem. $D=$ densidade global. 

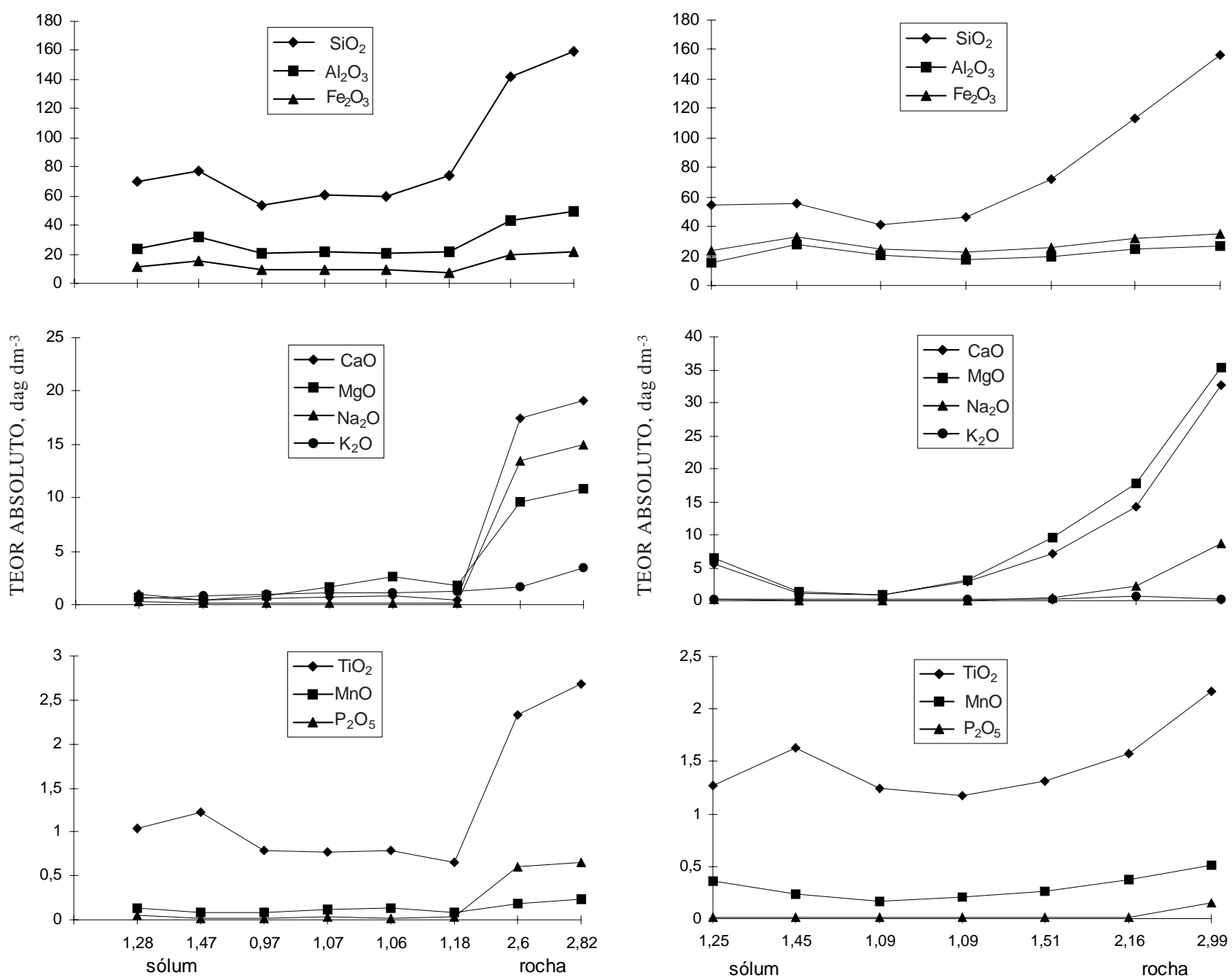

DENSIDADE, $\mathrm{kg} \mathrm{dm}^{-3}$

Figura 2. Diagramas de distribuição dos elementos maiores em teores absolutos versus densi dade para o perfil 2 - PVe.

nos perfis estudados, com exceção de ganho de $0,63 \%$ no horizonte $B_{t}$ do perfil 3 (MTf), apresentando perdas médias (desconsiderando o fácies rocha alterada) de cerca de 37, 50 e 33\%, respectivamente, nos perfis 1,2 e 3 . $\mathrm{O} \mathrm{Fe}_{2} \mathrm{O}_{3}$ apresentou perda moderada a moderada a baixa, com valores médios de 57, 51 e 25\%, respectivamente, nos perfis em epígrafe. Para o $\mathrm{TiO}_{2}$ as perdas médias foram de cerca de 32, 66 e $39 \%$ nos perfis 1, 2 e 3, respectivamente. Nos três perfis em pauta, os menores valores de perda de $\mathrm{Al}_{2} \mathrm{O}_{3}, \mathrm{Fe}_{2} \mathrm{O}_{3}$ e $\mathrm{TiO}_{2}$ foram encontrados nos horizontes $\mathrm{B}_{\mathrm{t}}$ de cada um dos perfis analisados, resultando num enriquecimento relativo desses constituintes químicos, ressaltandoseque, no perfil 3 (MTf), verificou-seenriquecimento real $(0,63 \%)$ de $\mathrm{Al}_{2} \mathrm{O}_{3}$.

CaO, MgO, $\mathrm{Na}_{\mathbf{2}} \mathbf{O}$ e $\mathbf{K}_{\mathbf{2}} \mathrm{O}$ - Os teores absolutos destes constituintes quími cos (Quadro 3) mostraram

perda geralmente acentuada ao longo da evolução da alteração intempérica, principalmente nas suas primeiras fases, da rocha fresca ao alterito, excetuando-se quando o teor inicial foi baixo. Do alterito até o sólum permaneceram praticamente constantes a baixíssimos valores. Somente no perfil 3 (MTf), observou-se um subseqüente acréscimo de $\mathrm{CaO}$ e $\mathrm{MgO}$ a partir do horizonte $\mathrm{B}_{\mathrm{t}}$ em direção ao horizonte A (Figuras 1, 2 e 3).

O balanço químico (Quadro 4) quantificou as perdas para o $\mathrm{CaO}, \mathrm{MgO}$ e $\mathrm{Na}_{2} \mathrm{O}$ em acentuadas a praticamente totais a partir do alterito (horizontes $C_{3}$ no perfil 2 - PVe e horizontes $C_{2}$ nos perfis 1 (PVAd) e 3 (MTf)), que praticamente se manteve com poucas variações, em direção ao sól um, apresentando valores de perda menores de magnitude variável dos fácies rocha fresca a rocha alterada. Nos perfis 1,2 e 3 , respectivamente, esses 
componentes químicos atingiram valores de perda de $99,58,97,98$ e $97,61 \%$ (CaO); 95, 16, 96,27 e $97,53 \%$ (MgO), e 97,73, 99,18 e 99,88\% ( $\left.\mathrm{Na}_{2} \mathrm{O}\right)$. O K ${ }_{2} \mathrm{O}$ nos perfis 1 (PVAd) e2 (PVe) apresentou comportamento semelhante, com perdas menos acentuadas, com val ores médios de cerca de 70\%. J á no perfil 3 - MTf, o comportamento do $\mathrm{K}_{2} \mathrm{O}$ mostrou ganhos e perdas, considerando o baixo teor de $\mathrm{K}_{2} \mathrm{O}$ na rocha original, comprometendo a análise do seu comportamento geoquímico.

MnO - De acordo com os dados de teores absolutos apresentados no quadro 3, este constituinte químico apresentou valores baixos em todos os perfis de alteração (Figuras 1, 2 e 3), apresentando, ao balanço químico, perda moderada de cerca de $50 \%$ para os perfis 2 (PVe) e 3 (MTf) (Quadro 4). No perfil 1 (PVAd), não foi possível o cálculo de balanço de massa, pois a rocha fresca de origem apresentou teor de $\mathrm{MnO}$ muito baixo, abaixo do limite inferior de detecção do método analítico adotado.

$\mathbf{P}_{\mathbf{2}} \mathbf{O}_{\mathbf{5}}$ - Apresentou comportamento semel hante ao descrito para $\mathrm{CaO}, \mathrm{MgO}, \mathrm{Na}_{2} \mathrm{O}$ e $\mathrm{K}_{2} \mathrm{O}$ nos perfis 2 (PVe) e 3 (MTf), sendo a perda menos significativa em relação aos seus baixos teores originais, conforme se pode observar nos dados de teores absolutos do quadro 3. No perfil 1 (PVAd), pode-se notar ligeiro acréscimo deste constituinte químico a partir do horizonte $\mathrm{C}_{2}$ em direção ao sól um, após perda a partir da rocha fresca (Quadro 3 e Figuras 1, 2 e 3).

Os dados do balanço químico (Quadro 4) mostraram perda acentuada e progressiva a partir do al terito, com val ores médi os de perda de 96 e $92 \%$, para os perfis 2 (PVe) e 3 (MTf), respectivamente. J á o perfil 1 (PVAd) mostrou perda média de cerca de $20 \%$ da rocha fresca ao horizonte $C_{1}$, invariável nos horizonte $B C$ e $B_{t}$, seguido de ganho de $37,50 \%$ no horizonte $A$.

Os resultados analíticos obtidos para os perfis 1 , 2 e 3 possibilitaram a análise da variação da composição química sofrida por eles ao longo da seqüência de alteração, desde a rocha fresca até o sól um. Os cál cul os vol umétri cos e o bal anço químico de massa permitiram avaliar o comportamento da mobilidade e distribuição dos elementos químicos ao longo da evolução pedogenética, bem como quantificar suas perdas e ganhos.

As magnitudes dos teores dos el ementos maioresóxidos constituintes aol ongo dos perfis de al teração mostraram-se compatíveis à composi ção química dos seus materiais originais, ou seja, rocha de composição granítica para o perfil 1 - Argissolo VermelhoAmarelo distrófico; rocha de composição diorítica para o perfil 2 - Argissol oVermel ho eutrófico; e rocha básica para o perfil 3 - Chernossol oArgilúvico férrico (Quadro 2). A variação química sofrida ao longo das seqüências de alteração pedogenética, da rocha fresca em direção ao sólum, é proporcional aos teores originais, o que se reflete em atributos dos solos formados, assim como a indi vidual ização em classes de solos com horizonte B textural distintas.

No entanto, verificou-se comportamento geoquímico semelhante para os três perfis em questão, marcado, em linhas genéricas, pela perda da mai oria dos constituintes quími cos nas primeiras fases da alteração, do fácies rocha fresca ao alterito, evidenciando quea alteração processa-serapidamente a partir do início da atuação intempérica.

O estudo pedogeoquímico mostrou que, ao longo da evolução da alteração, houve perdas moderadas de $\mathrm{SiO}_{2}$, da ordem de 50-60\%; perdas acentuadas a praticamentetotais, atingindo mais de $95 \%$ de $\mathrm{CaO}$, $\mathrm{MgO}$ e $\mathrm{Na}_{2} \mathrm{O}$ e menos acentuadas para o $\mathrm{K}_{2} \mathrm{O}$; perdas moderadas de $\mathrm{MnO}$, de cerca de $50 \%$; perdas acentuadas de $\mathrm{P}_{2} \mathrm{O}_{5}$ (média de $94 \%$ ), com exceção do perfil 1 (PVAd); perdas moderadas de $\mathrm{Al}_{2} \mathrm{O}_{3}$, moderadas a baixas de $\mathrm{Fe}_{2} \mathrm{O}_{3}$ e $\mathrm{TiO}_{2}$, mostrando enriquecimento relativo destes três últimos nos horizontes $B_{t}$ dos três perfis analisados.

Este comportamento geoquímico observado reflete, provavelmente o processo pedogenético e o grau de evol ução dos solos com horizonte B textural, concordando com as características dos solos dispostos em seqüências cronológicas e litológicas, discutidas por Resendeet al. (1995). É caracterizado por perda moderada de sílica, enriquecimento relativo moderado de Al e Fe e lixiviação de bases. Tal como descrito por Loughnan (1969), este comportamento mostra a lixiviação diferenciada de cátions no processo de meteorização de minerais primários, em que a extensão da alteração química ea natureza do produto residual formado dependem do grau de lixiviação sofrido pela rocha, conforme relatado por Carvalho (1995).

A dessilicatização moderada, juntamente com a perda moderada de $\mathrm{Al}_{2} \mathrm{O}_{3}$, pode ser verificada nas associações de argilominerais silicatados presentes nestes perfis de alteração, avaliados por Lacerda (1999) e Lacerda et al. (2000), que constataram a ocorrência de argilomineral 2:1 (illita, vermiculita com hidróxi nas entrecamadas, talco e esmectita), particularmente nos estádios iniciais da alteração horizontes C, em associação com argilomineral 1:1 (caulinita) e formação de gibbsita, geralmente nos horizontes subsuperficiais e superficiais $\left(B_{t} e A\right)$.

De acordo com Lacerda (1999) e Lacerda et al. (2000), no perfil 1 (PVAd), a associação deargilominerais silicatados é representada por illita (nos horizontes $\mathrm{C}$, BC e $\mathrm{B}_{\mathrm{t}}$ ) e caulinita + gibbsita (ambos nos horizontes $C, B C, B_{t}$ e $A$ ); o perfil 2 (PVe) apresenta illita (nos horizontes C eBC), vermiculita com hidróxi nas entrecamadas + caulinita (ambos nos horizontes $\mathrm{C}, \mathrm{BC}, \mathrm{B}_{\mathrm{t}} \mathrm{eA}$ ) e gibbsita (desenvolvendosea partir do horizonteBC), eo perfil 3 (MTf) mostra a associação caulinita +tal co +esmectita em toda a seqüência de horizontes individualizados. Estas 
associações de argilominerais silicatados e sua distribuição ao longo dos perfis estudados mostram processos evolutivos de bissialitização, monossialitização e até alitização para os perfis 1 (PVAd) e 2 (PVe), não atingindo a alitização no perfil 3 (MTf).

A lixiviação praticamente completa de $\mathrm{CaO}, \mathrm{MgO}$ e $\mathrm{Na}_{2} \mathrm{O}$ nos perfis analisados encontra-se diretamente relacionada com o baixo grau de resistência ao intemperismo dos minerais silicatados primários que os contêm e sua ordem de destruição intempérica ao longo da al teração, concor dando com a seqüência de intemperização de minerais primários estabelecida por Goldich (1938).

De acordo com os estudos mineralógicos real izados por Lacerda (1999) e Lacerda et al . (2000), nos perfis 1 (PVAd) e 2 (PVe), os minerais primários destruídos nos estádios iniciais da alteração intempérica são exatamente os silicatos ferromagnesianos e cálcio-sódicos, tais como os anfibólios (hornblenda-edenita) e os plagioclásios cálcio-sódicos, e, no perfil 3 (MTf), acrescenta-se a estes o clinopiroxênio (diopsídio-augita). Nos perfis 1 (PVAd) e 2 (PVe), o $\mathrm{K}_{2} \mathrm{O}$, em concordância com a ordem de perda de constituintes estabelecida por Polynov (1937), mostra lixiviação menos acentuada, primeiro pela estrutura do feldspato potássico, mineral de maior resistência ao intemperismo químico, e segundo, pela sua fixação na estrutura de argilominerais silicatados neo-formados, especialmente a illita (Besoain, 1985). No perfil 3 (MTf), o comportamento geoquímico do $\mathrm{K}_{2} \mathrm{O}$ é comprometido, em razão de seu baixo teor no material original.

O enriquecimento relativo de $\mathrm{Fe}_{2} \mathrm{O}_{3}, \mathrm{Al}_{2} \mathrm{O}_{3} \mathrm{eTiO}_{2}$ no horizonte $B_{t}$ é justificado pela concentração de sesquióxidos de Fe, Al eTi nessehorizonte (L acerda, 1999; Lacerda et al., 2000). Tais elementos são liberados, também, pela meteorização de minerais primários que os contêm na estrutura, tais como: silicatos ferromagnesianos (piroxênios e anfibólios), de acordo com a seqüência de intemperização destes estabelecida por Goldich (1938), além dos óxidos primários de Fe eTi. Esses constituintes, segundo Loughnan (1969), tornam-se progressivamente concentrados no resíduo, de acordo com sua menor mobilidade nas condi ções avaliadas e com os fatores que influenciam a mobilidade dos elementos, discutidas por Carvalho (1995), podendo o $\mathrm{Ti}^{4+}$ mostrar mobilidade se liberado como $\mathrm{Ti}(\mathrm{OH})_{4}$ e, se for liberado na forma $\mathrm{TiO}_{2}$, imobiliza-se; o $\mathrm{Fe}^{3+}$ imobiliza-se em condi ções oxi dantes; oAl ${ }^{3+}$ imobilizasenas variações de pH de 4,5 a 9,5. Percebeu-seque os teores de $\mathrm{Fe}_{2} \mathrm{O}_{3}$ nestes solos mostraram-se compatíveis, então, com os teores deste no material original, sendo o perfil 3 (MTf) o mais enriquecido nesse constituinte químico (11,58 dag kg$\left.{ }^{-1}\right)$, o perfil 1 (PVAd) o mais empobrecido (1,57 dag kg-1) eo perfil 2 (PVe) apresenta teor intermediário $\left(7,54\right.$ dag $\left.\mathrm{kg}^{-1}\right)$ (Quadro 2).
Por meio da análise de perdas dos principais elementos maiores-óxi dos constituintes ao longo dos três perfis avaliados, foi possível estabelecer a ordem de perda desses constituintes ao longo de toda a seqüência de alteração:

$$
\begin{aligned}
& \text { - Perfil } 1 \text { - PVAd: } \mathrm{Ca}>\mathrm{Na}>\mathrm{Mg}>\mathrm{K}>\mathrm{Si}>\mathrm{Fe}>\mathrm{Al} \\
& \text { - Perfil } 2 \text { - PVe: } \mathrm{Na}>\mathrm{Ca}>\mathrm{Mg}>\mathrm{K}>\mathrm{Si}>\mathrm{Al}>\mathrm{Fe} \\
& \text { - Perfil } 3 \text { - MTf: } \mathrm{Na}>\mathrm{Ca}>\mathrm{Mg}>\mathrm{Si}>\mathrm{K}>\mathrm{Al}>\mathrm{Fe}
\end{aligned}
$$

No perfil 3 (MTf), a posição ocupada pelo K é discutível, dado o seu baixo teor na rocha original, que compromete sua avaliação geoquímica. Com exceção deste, observa-se a mesma tendência de perda de constituintes e mobilidade dos cátions comuns nos solos, concordando, em linhas gerais, com a seqüência de perda de constituintes em solos, estabelecida por Polynov (1937), Goldich (1938) e Tyler (1958), citado por Loughnan (1969), e a mobilidade de cátions comuns em solos segundo Loughnan (1969).

Assim sendo, o primeiro grupo de constituintes lixiviados, com variações nas posi ções de per da para os três perfis, refere-se ao $\mathrm{Ca}, \mathrm{Mg}$ e $\mathrm{Na}$ que são rapidamente mobilizados e lixiviados. Segue-se o $\mathrm{K}$, quetambémérapidamente mobilizado elixiviado, mas a taxa de lixiviação pode ser retardada pela fixação na estrutura de illitas. O Si é mais lentamente lixiviado, seguido pelo Al eFe, visto que oAl ${ }^{3+}$ imobiliza-se nas variações de $\mathrm{pH}$ de 4,5 a 9,5 e o $\mathrm{Fe}^{3+}$ imobiliza-se em condições oxidantes, segundo Loughnan (1969).

\section{CONCLUSÕES}

1. Pela interpretação dos dados geoquímicos obtidos para os perfis estudados (PVAd, PVeeMTf), verificou-se, ao longo das seqüências de alteração pedogenética, variação química proporcional aos teores dos substratos litoquimicamente distintos.

2. Os cál culos vol umétricos e o balanço químico de massa permitiram constatar a mobilidade dos elementos químicos ao longo da evolução da alteração, com estabel ecimento de perdas e ganhos. Verificou-se comportamento geoquími co semel hante para os três perfis estudados, como reflexo do processo pedogenético e grau de evolução dos solos com horizonte B textural, caracterizado por perdas moderadas de Si (cerca de 50-60\%); perdas acentuadas a praticamente totais de $\mathrm{Ca}, \mathrm{Mg}$ e Na e menos acentuadas de $\mathrm{K}$; perdas moderadas de $\mathrm{Mn}$ (cerca de 50\%); perdas acentuadas deP (cerca de 9095\%) com exceção do perfil 1 (PVAd); perdas moderadas de Al, moderadas a baixas de Fe e Ti, com enriquecimento relativo destes três últimos nos horizontes $\mathrm{B}_{\mathrm{t}}$. 
3. Estabeleceu-se a seguinte ordem de perda dos constituintes maiores: Perfil 1 - PVAd: $\mathrm{Ca}>\mathrm{Na}>$ $\mathrm{Mg}>\mathrm{K}>\mathrm{Si}>\mathrm{Fe}>\mathrm{Al}$; Perfil 2 - PVe: $\mathrm{Na}>\mathrm{Ca}>\mathrm{Mg}>$ $\mathrm{K}>\mathrm{Si}>\mathrm{Al}>\mathrm{Fe}$; e Perfil 3 - MTf: $\mathrm{Na}>\mathrm{Ca}>\mathrm{Mg}>\mathrm{Si}$ $>\mathrm{K}>\mathrm{Al}>\mathrm{Fe}$

\section{LITE RATURA CITADA}

ANDRADE, H.; ALVES, H.M.R.; VIEIRA, T.G.C.; RESENDE, R.J .T.P.; ESTEVES, D.R; BRASIL, J.P.K. \& ROSA, E.R. Diagnóstico ambiental do município de Lavras com base em dados georreferenciados do meio físico: IV - Principais grupamentos de sol os. In: CONGRESSO BRASI LEIRO DE ENGENHARIA AGRí COLA, 27., Poços de Caldas, 1998. Anais. Poços de Caldas, Universidade Federal de Lavras/ Sociedade Brasileira de Engenharia Agrícola, 1998. v.4. p.442-443.

BESOAIN, E. Mineralogía de arcillas de suelos. San J osé, Costa Rica, I nstituto Interamericano de Cooperacion para la Agricultura, 1985. 1205p.

BONIFAS, M. Contribution à l'étude géochimique del'alteration latéritique. Mem. Serv. Carte Géol. d'Alsace et Lorraine, 17, 1959. 159p.

CARVALHO, I.G. Fundamentos da geoquímica dos processos exógenos. Salvador, Bureau, 1995. 213p.

EMPRESA BRASILEIRA DE PESQUISA AGROPECUÁRIA EMBRAPA. Serviço Nacional de Levantamento e Conservação de Solos. Manual de método de análise de solo. Rio de J aneiro, 1979a. não paginado.
EMPRESA BRASILEIRA DE PESQUISA AGROPECUÁRIA EMBRAPA. Serviço Nacional de Levantamento e Conservação de solos. In: REUNIÃO TÉCNICA DE LEVANTAMENTO DE SOLOS, 10., Rio de J aneiro, 1979. Súmula. Rio de J aneiro, 1979b. 83p. (SNLCS. Série Miscelânia, 1)

GOLDICH, S.A. A study in rock-weathering. J. Geol., 46:17-23, 1938.

LACERDA, M.P.C. Correlação geo-pedológica em solos B texturais na região de Lavras, MG. Lavras, Universidade Federal de Lavras, 1999. 257p. (Tese de Doutorado)

LACERDA, M.P.C.; ANDRADE, H. \& QUEMÉNEUR, J.J.G. Micropedogia da alteração em perfis de solos com $B$ textural na região de Lavras, Minas Gerais. R. Bras. Ci. Solo, 24:829-841, 2000.

LEMOS, R.C. \& SANTOS, R.D. Manual de descrição e coleta de solo no campo. 2.ed. Campinas. Sociedade Brasileira de Ciência do Solo, 1984. 45p.

LOUGHNAN, F.C. Chemical weathering of the silicate minerals. New York, Elsevier, 1969. 154p.

MILLOT, G. \& BONIFAS, M. Transformations isovolumetriques dans les phenomenes de laterisation et de bauxitisation. Bull. Serv. Carte Géol. d'Alsace et Lorraine, 8:3-20, 1955.

POLYNOV, B.B. The cyde of weathering. London, Thomas Murby, 1937. 220p.

QUÉMÉNEUR, J.J.G. Os magmatismos de idade Arqueana e Transamazônica na Região Campo das Vertentes, MG (Sul do Cráton São Francisco), com base em geoquímica e geocronologia. Belo Horizonte, Universidade Federal de Minas Gerais, 1995.79p.

RESENDE, M.; CURI, N.; REZENDE, S.B. \& CORRÊA, G.F. Pedologia: base para distinção de ambientes. Viçosa, NEPUT, 1995. 302p. 
M.P.C. LACERDA et al.

R. Bras. Ci. Solo, 26:75-85, 2002 